\title{
Multicolor fluorescence in situ hybridization on metaphase chromosomes and interphase Halo-preparations using cosmid and YAC clones for the simultaneous high resolution mapping of deletions in the dystrophin gene
}

\author{
Chintana Tocharoentanaphol ${ }^{1}$, Marion Cremer ${ }^{1}$, Evelin Schröck ${ }^{1}$, Lau Blonden ${ }^{2}$, Karin Kilian $^{1}$, \\ Thomas Cremer ${ }^{1}$, Thomas Ried \\ ' Institut für Humangenetik und Anthropologie der Universität, Im Neuenheimer Feld 328, D-69120 Heidelberg, Germany \\ ${ }^{2}$ Faculty of Medicine, Department of Genetics, Wassenaarseweg 72, 2300 RA Leiden, The Netherlands
}

Received: 17 August 1993/Revised: 20 October 1993

\begin{abstract}
We report on multicolor fluorescence in situ hybridization protocols for the simultaneous visualization of deletion-prone regions for carrier detection of Duchenne/ Becker (DMD/BMD) muscular dystrophy. Cosmid and yeast artificial chromosome (YAC) clones specific for preferentially deleted subregions of the dystrophin gene were labeled differentially and detected with three different fluorochromes using digital imaging microscopy. This approach allows for an assessment of the carrier status of female relatives even in families where no index patient is available. Cosmid and YAC clones, and different probegeneration protocols are compared with respect to their feasibility for carrier detection. The use of histone-depleted interphase nuclei (Halo-preparations) for deletion mapping is demonstrated and shown to have a resolution power of $5 \mathrm{~kb}$.
\end{abstract}

\section{Introduction}

Fluorescence in situ hybridization (FISH) has become a powerful tool both for basic research and diagnostic applications (for reviews see McNeil et al. 1991; Tkachuk et al. 1991; Lichter and Cremer 1992). This is attributable to recent technical improvements with respect to sensitivity, multiplicity, and resolution. DNA probes as small as $1 \mathrm{~kb}$ can be visualized on metaphase chromosomes (see e.g., Ried et al. 1993) and interphase chromatin (Lawrence et al. 1988), and protocols for Alu-polymerase chain reaction (PCR) amplification of yeast artificial chromosome (YAC) clones provide well-suited tools for interphase diagnosis, with a detection efficiency up to $99 \%$ (Lengauer

Correspondence to: T. Ried et al. $1992 \mathrm{a}, \mathrm{b})$. In addition, digital imaging devices, such as charge coupled device (CCD) cameras, contribute to increased sensitivity. Multiple haptenization and detection protocols, and combinatorial labeling approaches allow for the simultaneous visualization of several target regions in metaphase chromosomes and interphase nuclei (Nederlof et al. 1990; Ried et al. 1992a, b, c; Dauwerse et al. 1992; Lengauer et al. 1993; Wiegant et al. 1993). The high spatial resolution of fluorescent signals is improved considerably when extended chromatin preparations are used for FISH analysis (Heng et al. 1992; Wiegant et al. 1992). Moreover, with the progress of the Human Genome Project, an increasing number of DNA clones has become available (see e.g., Bellanné-Chantelot et al. 1992) that can be applied to specifically delineate chromosomal aberrations.

The diagnosis of carrier detection of Duchenne muscular dystrophy (DMD) requires the combination of these recent achievements of FISH. In more than $60 \%$ of cases, deletions of part of the dystrophin gene are responsible for the disease (Den Dunnen et al. 1989). These deletions are not randomly distributed over the $2.4 \mathrm{Mb}$ of genomic DNA that the gene covers on chromosome Xp21, but are clustered around exons 3-6 and 45-50 (Koenig et al. 1989; own observations). The use of FISH for carrier diagnosis has been demonstrated for one of the deletionprone regions (Ried et al. 1990). However, the simultaneous screening of hot spots is a perceived need in families where index patients are not available. In order to recognize the majority of deletion-prone regions, we present protocols for the simultaneous visualization of three deletion hot spots using multicolor FISH and digital image analysis. The use of different probes, such as cosmid and YAC clones, is compared with respect to the diagnostic requirements. High resolution deletion mapping is dem- 
onstrated using histone-depleted interphase nuclei (Halo preparations) from carriers of the disease.

\section{Materials and methods}

\section{Families}

Proband 1 is a manifesting carrier of a DMD family with a known deletion of exons 48-50. Her carrier status was confirmed by clinical evaluation, elevated creatine kinase levels, and haplotype analysis of polymorphic DNA probes flanking the deletion region. The lymphoblastoid cell lines used for Halo preparations were kindly provided by Dr. G. Wolff, Freiburg. Proband 2 is the mother and sister of DMD patients each with a large deletion including exons $12-48$ of the dystrophin gene. By pedigree analysis, she is an obligate carrier. Proband 3 is the mother of two DMD patients with a large deletion of exons $1-52$. The carrier status was determined by loss of heterozygosity of the deleted region of her children. Proband 4 is a manifesting DMD carrier, as diagnosed by elevated creatine kinase levels and an abnormal dystrophin pattern.

\section{DNA probes}

The DNA probes used in the multicolor experiments in this study are listed in Table 1, which also includes the exon content, the modified deoxynucleotides used for labeling, and the fluorescent detection format. The clones were kindly provided by Drs. A. Speer, Berlin-Buch (TM7, TM14), A.P. Monaco, Oxford (YACs $\left.5^{\prime}-1,5^{\prime}-3,3^{\prime}-11\right)$, and N. Dahl, Strasbourg $(\cos 9)$. The cosmid clone for exon 48 was isolated in Leiden.

\section{Metaphase spreads and interphase Halo preparations}

Human metaphase chromosomes were prepared following standard procedures (Verma and Babu 1989). Interphase Halos were prepared from adherently growing fibroblasts as described (Wiegant et al. 1992) with the following modifications. Fibroblasts cultured on slides were dipped into an extraction solution $(50 \mathrm{~m} M$ HEPES pH 7.8, $10 \mathrm{~m} M \mathrm{MgCl}_{2}, 0.5 \mathrm{~m} M \mathrm{CaCl}_{2}, 0.22 M$ sucrose, $0.5 \% \mathrm{NP} 40$ ) for $1.1 \mathrm{~min}$ at $0^{\circ} \mathrm{C}$, followed by a high salt histone extraction step in $0.2 \mathrm{M} \mathrm{MgCl}_{2}, 10 \mathrm{~m} M$ TRIS-HCl pH 7.4, with increasing concentrations of $\mathrm{NaCl}(0.2 M-1.8 M$, in steps, raising the salt concentration by $0.2 \mathrm{M}$ at each step). Finally, the slides were incubated in a solution containing $2 \mathrm{M} \mathrm{NaCl}, 0.2 \mathrm{mM} \mathrm{MgCl}_{2}, 10 \mathrm{mM}$ TRIS $\mathrm{pH} 7.4,5 \mu \mathrm{g} / \mathrm{ml}$ ethidium bromide. The DNA loops were subsequently stabilized by UV-nicking, and dehydrated through an ethanol series. DNA Halos from lymphoblastoid cell lines were prepared with minor modifications. Prior to the extraction, the cells were dropped onto glass slides. All extraction steps were performed as described above.

\section{Slot-blot analysis of PCR-amplified YAC clones}

Total yeast DNA containing dystrophin-gene-specific YAC clones (Monaco et al. 1992) was amplified with primers specific for exons known to be located in the respective YAC clones. Alu-PCR products from the same YAC clone were generated as described (Lengauer et al. 1992a,b). Both products were applied to Hybond membranes using a slot-blot apparatus. The filters were air-dried, baked at $80^{\circ} \mathrm{C}$ for $30 \mathrm{~min}$, followed by crosslinking with UV light. The DNA was denatured with $0.4 M \mathrm{NaOH}$, and neutralized with $0.2 M$ TRIS-HCl $/ 2 \times \mathrm{SSC}(1 \times \mathrm{SSC}=150 \mathrm{~m} M \mathrm{NaCl} / 15 \mathrm{~m} M$ sodium citrate), $\mathrm{pH} 7.5,30 \mathrm{~min}$ each. The membrane was again baked at $80^{\circ} \mathrm{C}$ for $2 \mathrm{~h}$, prehybridized for $1 \mathrm{~h}$ in $3 \mathrm{ml}$ hybridization buffer $(0.5 \%$ polyvinylpyrrolidone, $0.5 M$ EDTA, $1 M \mathrm{NaCl}, 50$ $\mathrm{mM}$ TRIS- $\mathrm{HCl} \mathrm{pH} 7.5,5 \%$ dextran sulfate, $0.2 \%$ heparin, $2.0 \%$ SDS at $65^{\circ} \mathrm{C}$ ). The filters were hybridized with biotinylated PCR products of 200 ng human genomic DNA, by using single exonspecific primers. The PCR products were labeled directly in the amplification reaction by substituting dTTP with biotin-11-dUTP (Sigma). Aliquots of $15 \mathrm{ng}$ amplification products were denatured in $25 \mu \mathrm{l}$ hybridization buffer supplemented with $2.5 \mu \mathrm{g}$ human Cotl DNA (BRL) at $95^{\circ} \mathrm{C}$ for $5 \mathrm{~min}$. Preannealing of repetitive sequences was allowed for $5 \mathrm{~min}$ at $37^{\circ} \mathrm{C}$. Hybridization took place overnight at $65^{\circ} \mathrm{C}$. The washing conditions and the detection procedures with chemieluminescence was performed as described earlier (Bronstein et al. 1990). Signals were evaluated by visual inspection.

\section{Probe labeling and FISH analysis}

Probe labeling was performed via nick translation (Sambrook et al. 1989) by substituting dTTP with either biotin-11-dUTP (Sigma), digoxigenin-11-dUTP (Boehringer Mannheim), or dinitrophenol (DNP)-11-dUTP (Novagen) (see Table 1 for the cosmid assignment). Aliquots of $80 \mathrm{ng}$ of each cosmid or Alu-PCR product were precipitated in the presence of $10 \mu \mathrm{g}$ salmon sperm DNA and $5 \mu \mathrm{g}$ human Cot1 DNA (BRL). The DNA was resuspended in $10 \mu \mathrm{l}$ hybridization solution (50\% formamide, $10 \%$ dextran sulfate, $2 \times$ SSC), denatured at $75^{\circ} \mathrm{C}$ for $5 \mathrm{~min}$, allowed to preanneal at $37^{\circ} \mathrm{C}$ for $20 \mathrm{~min}$, and applied to previously denatured metaphase chromosomes (slides were denatured at $75^{\circ} \mathrm{C}$, for $2 \mathrm{~min}$, in $70 \%$ formamide, $2 \times \mathrm{SSC}$, pH 7.0, and dehydrated through an ethanol series). An $18 \times 18 \mathrm{~mm}$ coverslip was added and sealed with rubber cement. Hybridization took place overnight at $37^{\circ} \mathrm{C}$. In triple-color FISH analysis, the biotinylated sequences were detected with avidin-Cy5 (Jackson ImmunoResearch Laboratories), digoxigenindUTP with anti-digoxigenin-conjugated rhodamine (Boehringer Mannheim), and the DNP-labeled probes by using a rat monoclonal antibody against DNP (Novagen), followed by incubation with anti-rat IgG coupled to fluorescein isothiocyanate (FITC) (Sigma). Images were recorded using an epifluorescence micro-

Table 1. Probes used in the multicolor FISH experiments

\begin{tabular}{lcll}
\hline Probe & Exon & Label & Detection \\
\hline Cosmid TM7 & 52 & DNP & FITC \\
Cosmid TM14 & 50 & Dig & Rhodamine \\
Cosmid MA 2B3 & 48 & Bio & Cy 3 \\
Cosmid cpt 1 & 45 & Bio/or Dig & Cy 5/or FITC \\
YAC 5'-1 & $3-9$ & DNP & FITC \\
YAC 5'-3 & $8-17$ & Dig & Rhodamine \\
YAC 3'-11 & $34-52$ & Bio & Cy 5 \\
\hline
\end{tabular}

Bio, Biotin; DNP, dinitrophenol; Dig, digoxigenin; FITC, fluorescein isothiocyanate

Fig. 1A-G. Examples of simultaneous FISH analysis with cosmid clones specific for the dystrophin gene on metaphase chromosomes. A-D Three differentially labeled cosmid clones were hybridized to metaphase chromosomes of a female patient with DMD (proband 4). The composite image shows labeling on both $\mathrm{X}$ chromosomes for all clones, indicating two copies respectively. A DAPI counterstain. The X chromosomes are denoted with arrows. B Cosmid TM14. C Cosmid cpt1. D Cosmid TM7. Each clone hybridized to both $\mathrm{X}$ chromosomes. $\mathbf{E}-\mathbf{G}$ The same cosmid set as in A was hybridized to metaphase chromosomes from a female relative of a patient with DMD (proband 1). The cosmid clone specific for exon 50 (TM14) labeled only one of the X chromosomes ( $a r$ rows) (E), whereas the clones for exon 45 and 52 were present in two copies (arrows) (F, G). This indicates a deletion for exon 50 


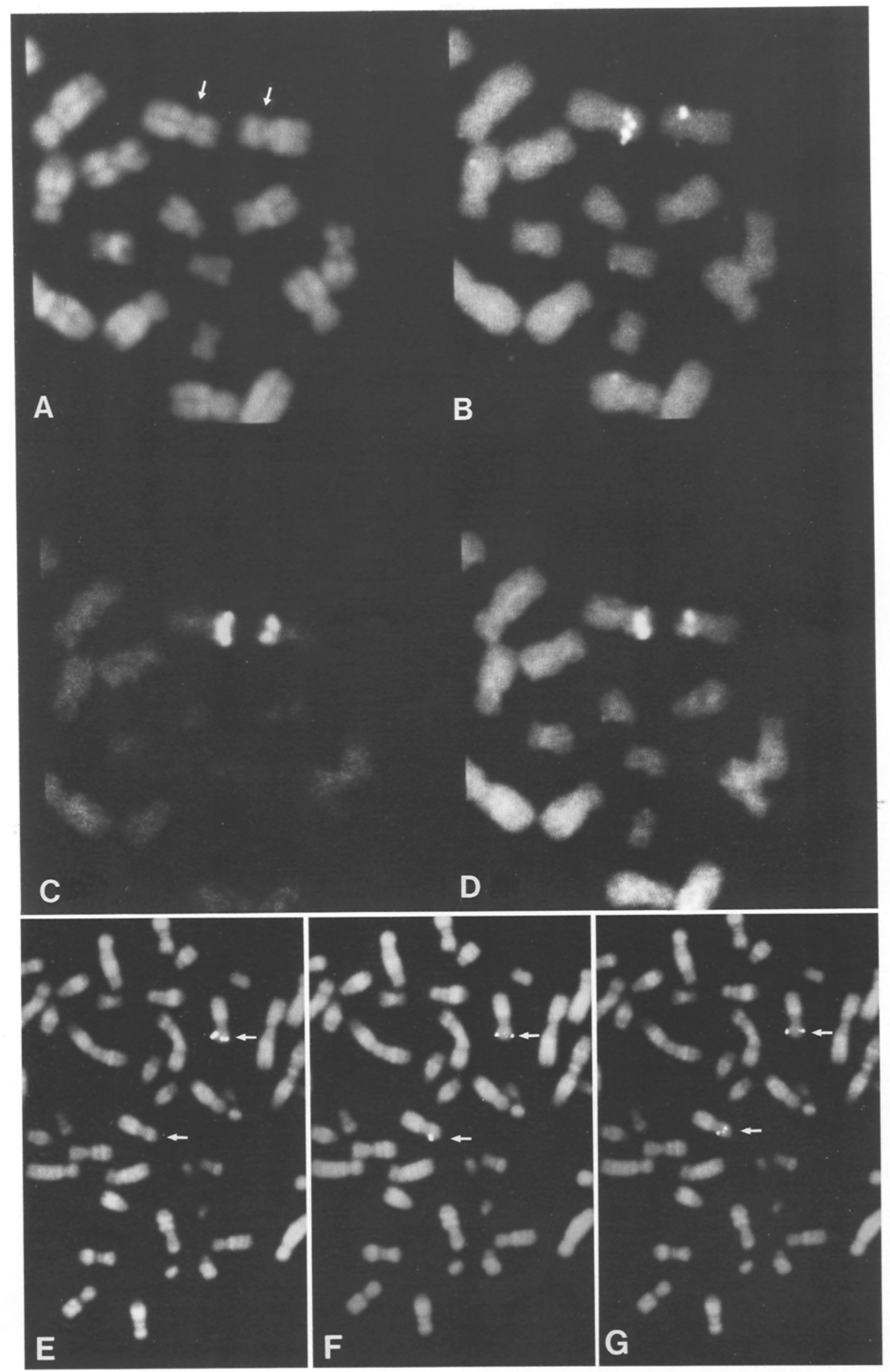



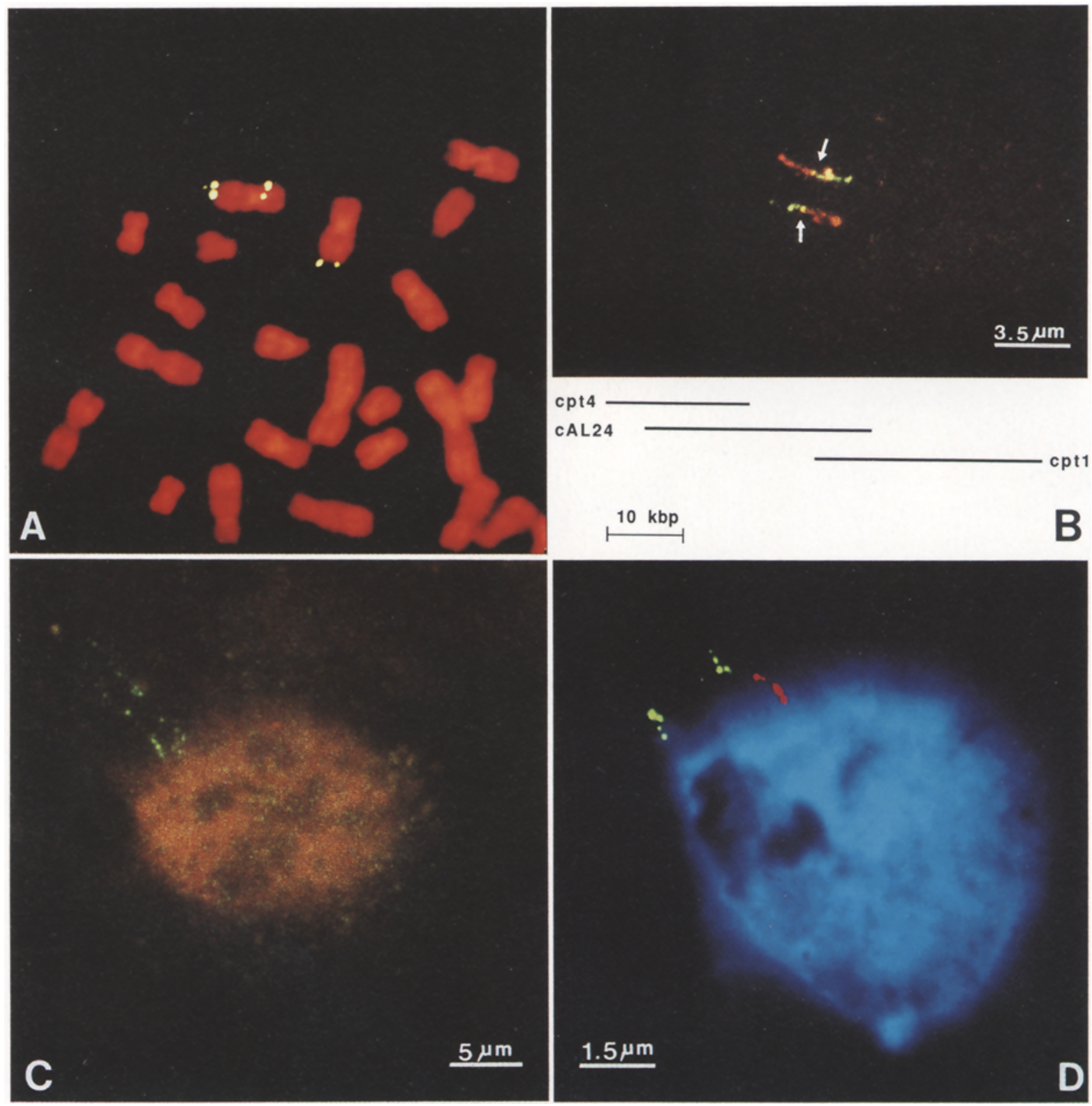

Fig. 2A-D. Examples of deletion mapping with YAC and cosmid clones on metaphase chromosomes and interphase Halo preparations. A YAC clone $3^{\prime}-11$ was hybridized to metaphase preparations from a female relative of a patient with DMD (proband 2). As a hybridization control, a cosmid clone specific for chromosomal mapping position $\mathrm{Xq}(\cos 9)$ was cohybridized. The YAC clone signal on the short arm of the $X$ is present in one copy, and the control sequence in two copies, indicating a deletion of the genomic region covered by the YAC clone containing exons 34-52. B The resolution power using interphase Halos was tested in a two-color experiment by double-labeling overlapping cosmid clones specific for the genomic region around exon 45 (Blonden et al. 1989). With restriction mapping, the overlap region, schematically presented in the lower part of the figure, was determined to be $7 \mathrm{~kb}$. The cosmid

scope (Zeiss Axiophot) equipped with a cooled CCD camera (Photometrics) and filter sets specific for the employed fluorochromes. Gray scale images were pseudocolored and merged as described in detail elsewhere (Ried et al. 1992b). The fluorescent images from the interphase Halos (see Fig. 2b,c) were obtained with a Leica DM RBE microscope equipped for epifluorescence, and were recorded on color slide film after double exposures. clones appear as pure-colored string-like signals on the extended DNA fiber. The overlap region is indicated by a merged color (yellow) in the center of the hybridization signal (arrows). C Hybridization of YAC clone $3^{\prime}-11$ to interphase Halos from a male proband. As expected, only one signal can be observed. The 800 $\mathrm{kb}$ of genomic sequences cloned in the YAC label an entire DNA loop. D Example of a high resolution deletion mapping using Halo preparations from lymphoblastoid cell lines. Two cosmid clones were differentially labeled and hybridized to a Halo preparation from a carrier of DMD (proband 1). The intact X chromosome is visible as colocalized red and green labeling. The $\mathrm{X}$ chromosome carrying the deletion shows only a green signal, indicating a deletion for exon 48

\section{Results}

In order to test the feasibility of multicolor FISH for the simultaneous visualization of deletion-prone regions in the dystrophin gene, we employed differential labeling of cosmid clones specific for exons 45,50 , and 52 . The la- 
beling scheme is reported in Table 1. As expected from the experimental design, signals were detected with either of the employed fluorochromes on metaphase spreads from normal female controls (data not shown). In order to analyze the molecular character of the aberration in a female patient who had a normal karyotype but who was suffering from DMD, the probe set was hybridized to metaphase spreads from proband 4 (Fig. 1A-D). The images were recorded sequentially, because the resolution of metaphase chromosomes is not sufficient for simultaneous display in a merged image. All three cosmids revealed signals using the filter sets specific for the employed fluorochromes. This indicated that the molecular mechanism was either a deletion elsewhere in the dystrophin gene, or a different event (e.g., a point mutation). The probe cocktail was then hybridized to metaphase preparations of proband 1 . The cosmid probes cpt 1 and $\mathrm{TM} 7$ revealed signals on both $\mathrm{X}$ chromosome homologs, indicating the presence of two copies of this genomic region. Clone TM14, however, labeled only one X chromosome (Fig. $1 E-G)$. These findings confirmed the patient's carrier status, previously assumed by linkage analysis and clinical data. In an additional experiment, the cosmid pool was hybridized to metaphase spreads of proband 3. For all clones used, only one of the $\mathrm{X}$ chromosomes was labeled, indicating a deletion that extends at least from exon 45 to exon 52 (not shown).

YAC clones are reported to result in excellent hybridization efficiency after Alu-PCR amplification of human sequences (Lengauer et al. 1992a,b). This property and the fact that the entire dystrophin gene is available as a YAC contig (Monaco et al. 1992) prompted us to test whether YAC clones are suitable tools for deletion screening in DMD carriers. Prior to our analysis, the exon content of each YAC clone was confirmed with PCR using primers specific for certain exons of the dystrophin gene (data not shown). Differential labeling of the YAC clones was performed as described for the cosmid clones (Table 1). The sequentially reported images for the different fluorochromes revealed two signals in all fluorescent colors on normal female metaphase chromosomes (data not shown). This probe pool was then hybridized to metaphase spreads of proband 1. Two signals were detected for each of the YAC clones. The partial deletion of the dystrophin gene on one of the $\mathrm{X}$ chromosomes could therefore not be visualized (data not shown). Figure 2A shows an example of an entirely deleted YAC clone. Using a reference probe for the long arm of the $X$ chromosome, a carrier of DMD could be delineated with the YAC clone $3^{\prime}-11$, since hybridization signals could be observed on the short arm only on one of the $\mathrm{X}$ chromosomes. This is in agreement with the predicted carrier status from previous FISH experiments using the cosmid clone cpt1, and from results of the pedigree analysis.

Alu-PCR amplification of human sequences does not entirely represent the genomic information of a given clone, since the amplification depends on the repeat distance and orientation. Thus, the position of the Alu-PCR products with respect to the human genomic sequence in the YAC clone is not known. We examined the representation of exon sequences in the Alu-PCR products with a

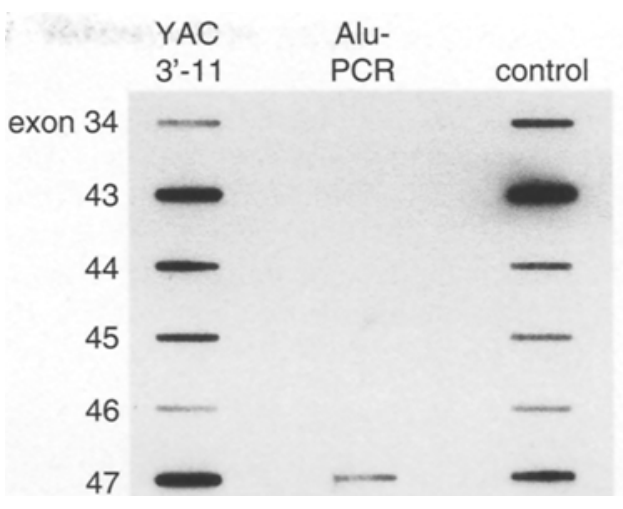

Fig.3. Slot-blot analysis of the exon content of YAC clone $3^{\prime}-11$ after Alu-PCR amplification. All exons are present in the YAC DNA (left lane), and in genomic DNA from a healthy donor (right lane). Only exon 47 was detectable in the Alu-PCR products of the YAC clone (center lane)

slot-blot filter assay. Alu-PCR products of all three YAC clones were blotted, as were PCR products of these YAC clones after amplification with exon-specific primers. The blotted DNA was hybridized with PCR products from total genomic DNA prepared from a healthy male, using identical exon-specific primers. The presence of each of the exons could be confirmed in the DNA of all of the YAC clones. Four exons were tested for YAC clones $5^{\prime}-1$ and $5^{\prime}-3$, respectively. None of them was maintained after Alu-PCR amplification. The Alu-PCR products revealed a signal after exon-specific hybridization in only one out of 10 exons investigated for the YAC clone $3^{\prime}-11$. This indicates that exon sequences of the dystrophin gene are scarcely represented in Alu-PCR products from YAC clones (Fig. 3).

Signals on metaphase chromosomes can be resolved spatially only if they are at least some $2-5 \mathrm{Mb}$ apart from each other. The hybridization signals of the cosmid clones specific for certain subregions of the dystrophin gene could therefore only be identified by means of their distinct color in consecutively recorded images with filter sets specific for the employed fluorochromes. Histonedepleted interphase nuclei, however, reveal a largely increased resolution (Wiegant et al. 1992). By using partially overlapping cosmid clones from the genomic region of exon 45 (Blonden et al. 1989), we were able to visualize, in a two-color experiment, an overlap region of $5 \mathrm{~kb}$. This was indicated by a merged color (yellow) flanked by pure fluorochromes (red and green) at either end of the extended DNA string of the chromatin fiber (Fig. 2B). Figure $2 \mathrm{C}$ shows an example of Alu-PCR products from YAC clone $3^{\prime}-11$ hybridized to Halo preparations. The YAC clone contained human sequences of $800 \mathrm{~kb}$. Only one extended signal, labeling an entire loop, could be observed, (as expected) in a male proband. The extent of the YAC clone exceeds the average sizes reported for DNA loops after histone depletion, which are up to $180 \mathrm{~kb}$ (Nelson et al. 1986). In order to apply Halo preparations for high resolution deletion mapping in carriers of DMD, we modified the described protocol for interphase nuclei from lymphoblastoid cell lines. Halo preparations of an obligate carrier (proband 1) were hybridized with neighboring 
DNA clones specific for exons 45 and 48 in a two-color experiment. Two signals were detected for the green fluorescence (exon 45). Only one additional red signal (exon 48) was observed. Exon 45 and 48 are approximately 100 $\mathrm{kb}$ apart from each other. The colocalization of the red and green signal reflects the physical distance of the two clones, which are presumably located on one DNA loop, and displays with high resolution the deletion of exon 48 in the dystrophin gene (Fig.2D).

\section{Discussion}

Carrier-status diagnosis of female relatives from a patient with DMD is readily peformed with FISH when the extent of the deleted region in the patient is known and suitable DNA clones for this region are at hand (Ried et al. 1990). However, in cases where no index patient is available, carrier-status diagnosis requires screening for the frequently involved deletion regions. We have therefore established a multicolor FISH approach that allows for the simultaneous visualization of three preferentially deleted regions. In normal female controls, hybridization signals with each of the employed fluorochromes are expected on both homologs of the $\mathrm{X}$ chromosome. In females carrying a deletion, the signal specific for the clone of the deleted genomic region is not visible. Signals from adjacent clones serve as a hybridization control, a fact that is particularly advantageous when interphase nuclei are examined, since the outline shape of the metaphase chromosome cannot be used to judge signal assignment, and fluorescent background spots might be considered as real signals.

In addition to cosmids, YAC clones provide a promising diagnostic tool in FISH analysis of chromosomal aberrations (Lengauer et al. 1992a,b). We have therefore compared these two types of probes with respect to the feasibility of deletion mapping in DMD. Rapid reproducible probe generation protocols are a necessity in applying probes in diagnostic settings. Whole yeast DNA, labeled via nick translation does not fulfill these requirements, since the hybridization signals are poor and background fluorescence caused by the excess of vector DNA is high. With the emergence of interspersed repeat sequence PCR protocols (Nelson et al. 1989; Ledbetter et al. 1990) that selectively amplify the human content in a background of, for example, hamster hybrid cell lines (Lengauer et al. 1990; Lichter et al. 1990), YAC clones became suitable probes for FISH in diagnostic settings. Alu repeats (Deininger et al. 1981) are the most common repeat sequences in man, with a copy number of about $10^{6}$. This results in an average distance of the repeat of about $4 \mathrm{~kb}$ (for a review, see Kariya et al. 1987). However, the consensus sequences are not evenly distributed in the genome, but are enriched in R-bands (Korenberg and Rykowski 1988). Moreover, the distance between two repeats may vary considerably. The amplification of YAC clones with Alu primers typically results in a number of sequences of varying size. The distribution of the amplification products on the genomic target is not known. We therefore compared the degree of amplified sequences with the nick translation of entire YAC clones. The result indicated that, in only one of the three YAC clones tested, one out of 10 exons of the respective genomic region was amplified. Alu-PCR of two additional YAC clones failed to amplify any exon sequences. In addition, the average YAC clone size often exceeds the size of frequent deletions. Both facts let us conclude that, for deletion detection in the dystrophin gene, the use of cosmid clones is preferable to the use of YAC clones, when employing FISH.

In about $70 \%$ of all deletions found in our patients ( $n=$ 84 , data not shown), at least one of the exons that are contained in the cosmids used in our study is involved. Nevertheless, the effective detection rate of carriers is lower because the extent of a deletion may be smaller than the length of the DNA fragment of the respective cosmid (manuscript in preparation).

The resolution limit of metaphase chromosomes is in the range of some $5 \mathrm{Mb}$. Multiple clones for the deletionprone regions can therefore only be resolved by means of their respective color. Extended chromatin preparations using either inhibitors of topoisomerase II (Heng et al. 1992) or protocols that result in histone depletion of chromatin, termed Halo preparations, provide a considerably improved resolution (Wiegant et al. 1992). The feasibility of these preparations for FISH analysis was shown using adherently growing fibroblasts (Wiegant et al. 1992). The extraction procedure results in extended DNA loops that surround a matrix fraction that is thought to represent the nuclear scaffold (Vogelstein et al. 1980; Mirkovitch et al. 1984). We have prepared Halos from lymphoblastoid cell lines of a carrier of DMD. Using these structures, high resolution mapping of genomic subclones of the dystrophin gene has become possible. The resolution limit is in the range of $5 \mathrm{~kb}$. This should allow us to investigate whether a clone is entirely deleted or present in both copies. By comparing the length of signals on both homologous chromosomes, it should be possible to assess whether partial deletions are present, as reflected by a shortened signal length. In a subsequent FISH experiment using smaller probes, e.g., phage or plasmid clones in a multicolor experiment, partial deletions can then be confirmed. We presume that this high resolution mapping on interphase Halo preparations will not only shed light on the extent of common deletions in the dystrophin gene. It should also become clear whether certain sequences of the gene, such as promotors or exon/intron boundaries are preferentially attached to the nuclear matrix fraction. In addition, the distribution of expressed versus repressed genes, as ideally modelled on the active and inactive $\mathrm{X}$ chromosome, can be investigated.

Acknowledgements. C.T. received a stipend from the Deutsche Akademische Austauschdienst, and T.R. a postdoctoral fellowship from the Deutsche Forschungsgemeinschaft. This study was supported in parts by grants from the Deutsche Forschungsgemeinschaft and the European Community to T.C. The authors wish to thank Drs. N. Dahl, Strasbourg, A. Monaco, London, and A. Speer, Berlin-Buch, for kindly providing the DNA clones. The skilled technical assistence of M.C. Meffert is gratefully acknowledged. The Cy 5 filter was kindly provided by Carl Zeiss, Oberkochen. The authors are gratefull to Prof. Dr. Dr. h.c. F. Vogel for his continuous support and encouragement. 


\section{References}

Bellanné-Chantelot C, Lacroix B, Ougen P, Billaut A, Beaufils S, Betrand S, Georges I, Gilbert F, Gros I, Lucotte G, Susini L, Codani JJ, Gesnouin P, Pook S, Vaysseix G, Lu-Kuo J, Ried T, Ward DC, Chumakov I, Le Paslier D, Barillot E, Cohen D (1992) Mapping the whole human genome by fingerprinting yeast artificial chromosomes. Cell 70:1059-1068

Blonden LAJ, Den Dunnen JT, Paassen HMB van, Wapenaar MC, Grootscholten PM, Ginjaar HB, Bakker E, Pearson PL, Ommen GJB van (1989) High resolution deletion breakpoint mapping in the DMD gene by whole cosmid hybridization. Nucleic Acids Res 17:5611-5621

Bronstein I, Voyta JC, Lazzari KG, Murphy O, Edwards B, Kricka LJ (1990) Rapid and sensitive detection of DNA in Southern blots with chemieluminescence. Biotechniques 8:310-314

Dauwerse JG, Wiegant J, Raap AK, Breuning MH, Ommen GJB van (1992) Multiple colors by fluorescence in situ hybridization using ratio-labelled DNA probes create a molecular karyotype. Hum Mol Genet 1:593-598

Deininger PL, Douglas JJ, Rubin CM, Friedman T, Schmid CW (1981) Base sequences studies of 300 nucleotide renatured human DNA clones. J Mol Biol 151:17-33

Den Dunnen JT, Grootscholten PM, Bakker E, Blonden LAJ, Ginjaar HB, Wapenaar MC, Paassen HMB van, Broeckhoven C van, Pearson PL, Ommen GJB van (1989) Topography of the DMD gene: FIGE and cDNA analysis of 194 cases reveals 115 deletions and 13 duplications. Am J Hum Genet 45:835-847

Heng HHQ, Squire J, Tsui J-C (1992) High resolution mapping of mammalian genes by in situ hybridization to free chromatin. Proc Natl Acad Sci USA 89:9509-9513

Kariya Y, Kato K, Hayashizaki Y, Hineeno S, Tarni S, Matsubaru K (1987) Revision of consensus sequence of human Alu repeats: a review. Gene $53: 1-60$

Koenig M, et al (1989) The molecular basis for Duchenne versus Becker muscular dystrophy: correlation of severity with type of deletion. Am J Hum Genet 45:498-508

Korenberg JR, Rykowski MC (1988) Human genome organization: Alu, Lines, and the molecular structure of metaphase chromosomes. Cell $53: 391-400$

Lawrence JB, Villnave CA, Singer RH (1988) Sensitive, high-resolution chromatin and chromosome mapping in situ: presence and orientation of two closely integrated copies of EBV in a lymphoma cell line. Cell 52:51-61

Ledbetter SA, Nelson DL, Warren ST, Ledbetter DH (1990) Rapid isolation of DNA probes within specific chromosome regions by interspersed repetitive sequences polymerase chain reaction. Genomics 6:475-481

Lengauer C, Riethmann H, Cremer T (1990) Painting of human chromosomes with probes generated from hybrid cell lines by PCR with Alu and L1 primers. Hum Genet 86:1-6

Lengauer C, Green ED, Cremer T (1992a) Fluorescence in situ hybridization of YAC clones after Alu-PCR amplification. Genomics 13:826-828

Lengauer C, Riethmann HC, Speicher MR, Taniwaki M, Konecki D, Green ED, Becher R, Olson MV, Cremer T (1992b) Metaphase and interphase cytogenetics with Alu-PCR-amplified yeast artificial chromosome clones containing the BCR gene and the protooncogenes c-raf-1, c-fms, and c-erbB-2. Cancer Res 52:2590-2596

Lengauer C, Speicher MR, Popp S, Jauch A, Taniwaki M, Nagaraja $\mathrm{R}$, Riethman $\mathrm{HC}$, Donis-Keller H, U'Urso M, Schlessinger D, Cremer T (1993) Chromosomal bar codes produced by multicolor fluorescence in situ hybridization with multiple YAC clones and whole chromosome painting probes. Hum Mol Genet 2:505-512

Lichter P, Ledbetter SA, Ledbetter DH, Ward DC (1990) Fluorescence in situ hybridization with Alu and L1 polymerase chain reaction probes for rapid characterization of human chromosomes in hybrid cell lines. Proc Natl Acad Sci USA 87:66346638

Lichter P, Cremer T (1992) Chromosome analysis by non-isotopic in situ hybridization. In: Human cytogenetics: a practical approach. IRL, Oxford, pp 157-192

Mirkovitch J, Mirault M-E, Laemmli UK (1984) Organization of higher-order chromatin loop: specific DNA attachment sites on nuclear scaffold. Cell 39:223-232

McNeil JC, Johnson CV, Carter KC, Singer RH, Lawrence JB (1991) Localizing DNA and RNA within nuclei and chromosomes by fluorescence in situ hybridization. Genet Anal Techn Appl 8:2

Monaco AP, Walker AP, Millwood I, Larin Z, Lehrach H (1992) A yeast artificial chromosome contig containing the complete Duchenne Muscular dystrophy gene. Genomics 12:465-473

Nelson DL, Ledbetter SA, Corbo L, Victoria MF; Ramirez-Solis R, Webster T, Ledbetter DH, Caskey CT (1989) Alu polymerase chain reaction: a method for rapid isolation of humanspecific sequences from complex DNA sources. Proc Natl. Acad Sci USA 86:6686-6690

Nelson WG, Pienta KJ, Barrack ER, Coffey DS (1986) The role of the nuclear matrix in the organization and function of DNA. Ann Rev Biophys Chem 15:457-475

Nederlof P, Flier S van der, Wiegant J, Raap AK, Tanke HJ, Ploem JS, Ploeg M van der (1990) Multiple fluorescence in situ hybridization. Cytometry $11: 126-131$

Ried T, Mahler V, Vogt P, Blonden L, Ommen GJB van, Cremer T, Cremer M (1990) Direct carrier detection by in situ suppression hybridization with cosmid clones of the Duchenne/ Becker muscular dystrophy locus. Hum Genet 85:581-586

Ried T, Lengauer C, Cremer T, Wiegant J, Raap AK, Ploeg $M$ van der, Groitl P, Lipp M (1992a) Specific metaphase and interphase detection of the breakpoint region in $8 \mathrm{q} 24$ of Burkitt lymphoma cells by triple color fluorescence in situ hybridization. Genes Chromosom Cancer 4:69-74

Ried T, Baldini A, Rand TC, Ward DC (1992b) Simultaneous visualization of seven different DNA probes using combinatorial fluorescence and digital imaging microscopy. Proc Natl Acad Sci USA 89:1388-1392

Ried T, Landes G, Dackowski W, Klinger K, Ward DC (1992c) Multicolor fluorescence in situ hybridization for the simultaneous detection of probe sets for chromosomes 13,18,21, X, and $\mathrm{Y}$ in uncultured amniotic fluids cells. Hum Mol Genet 1:307313

Ried T, Rudy B, Vega-Saenz de Miera E, Lau D, Ward DC, Sen L (1993) Localization of a highly conserved human potassium channel gene (NGK2-NV4; KCNC1) to chromosome $11 \mathrm{p} 15$. Genomics 15:405-411

Sambrook J, Fritsch EF, Maniatis T (1989) Molecular cloning: a laboratory manual. Cold Spring Harbor Laboratory, Cold Spring Harbor, NY

Tkachuk DC, Pinkel D, Kuo W-L, Weier H-U, Gray JW (1991) Clinical applications of fluorescence in situ hybridization. Genet Anal Techn Appl 8:67-74

Verma RS, Babu A (1989). Human chromosomes: manual of basic techniques. Pergamon Elmsford

Vogelstein B, Pardoll DM, Coffey DS (1980) Supercoiled loops and eucaryotic DNA replication. Cell 22:79-85

Wiegant J (1993) Multiple and sensitive fluorescence in situ hybridization with rhodamine-, fluorescein-, and coumarin-labeled DNAs. Cytogenet Cell Genet 63:73-76

Wiegant J, Kalle W, Mullenders L, Brookes S, Hoovers JMN, Dauwerse JG, Ommen GJB van, Raap AK (1992) High-resolution in situ hybridization using DNA halo preparations. Hum Mol Genet 1:587-591 